\title{
The Influence of Social Class on University Students' Prosocial Behavior Based on the Game Perspective
}

\author{
Hao Ding $\mathbb{D}^{1}{ }^{1}$ Feng Xu $\mathbb{D}^{2},{ }^{2}$ and Jia-Ming Zhu $\mathbb{D}^{2}$ \\ ${ }^{1}$ School of Literature and Education, Bengbu University, Bengbu 233030, China \\ ${ }^{2}$ School of Statistics and Applied Mathematics, Anhui University of Finance and Economics, Bengbu 233030, China \\ Correspondence should be addressed to Jia-Ming Zhu; zhujm1973@163.com
}

Received 13 March 2021; Revised 28 March 2021; Accepted 5 April 2021; Published 13 April 2021

Academic Editor: Shenggang Li

Copyright (c) 2021 Hao Ding et al. This is an open access article distributed under the Creative Commons Attribution License, which permits unrestricted use, distribution, and reproduction in any medium, provided the original work is properly cited.

In the present research, based on the game research paradigm, the research tools are the dictator game and the trust game, and the research objects are Chinese university students. We adopt 2 (self-social class: high, low) $\times 2$ (target social class: high, low) betweensubjects design experiment to investigate the influence of social class on university students' prosocial behavior. Across the experimental study, we find that (1) in the two situations of dictator game and trust game, self-social class has no significant influence on university students' prosocial behavior; (2) in the situation of dictator game, target social class has a significant influence on university students' prosocial behavior, and it is regulated by self-social class. Under the condition of low self-social class, the higher the target social class, the more prosocial behavior of university students, which confirms the perspective of status and negates "if you are poor, you will be good for yourself." Under the condition of high self-social class, the lower the target social class, the more prosocial the behavior of university students, which confirms the perspective of fairness and echoes "if you are good, you will be good at the world"; (3) in the context of the trust game, target social class has a significant influence on university students' prosocial behavior, and there is no interaction effect with self-social class.

\section{Introduction}

Social class has always been the subject of economics and sociology. In recent years, the role of social class in shaping individual behavior has attracted increasing attention in the field of psychology. Prosocial behavior refers to all behaviors that voluntarily benefit others, including all positive and socially responsible behaviors such as helping others, sharing, humility, cooperation, comfort, donation, selfsacrifice, voluntary service, and trust [1]. So, how does social class influence prosocial behavior? Researchers have conducted a series of rich studies on this. Piff et al. believe that the lower the social class, the more the prosocial behavior [2]. In other words, the poorer people are, the more willing they are to give; the richer they are, the more they will be unscathed. In a relatively long period of time, the research conclusions of Piff et al. have been cited a lot and spread widely around the world. But some researchers believe that the higher the social class, the more the prosocial behavior
$[3,4]$. It can be seen that there are extremely sharp controversies in previous studies. What is more, the scope of controversy is still expanding. Some researchers believe that social class is related to prosocial behavior, but self-social class has little to do with prosocial behavior, and target social class is more important than self-social class [5]. In addition, the same research has found diametrically opposite conclusions on research objects in different countries such as China and the United Kingdom [6, 7]. Cross-cultural research shows that countries or cultures may be important moderators. Ancient Chinese "Mencius" said. "If you are poor, you will be good for yourself, and if you are good, you will be good at the world." Poverty and prosperity can be described as simple expressions of social class; independent and good-for-all are the perfect annotations of prosocial behavior. Modern Chinese economy has experienced rapid development for decades. The words of bottom, blue-collar, middle class, and upper class are commonly used words in the Chinese public opinion circles, and terms such as "Xue 
Ba" and "Xue Zha" are also popular on university campuses. The important direction of contemporary Chinese college students' mental health education is to guide college students to correctly understand righteousness and benefit, group and self, success and failure, and gain and loss and cultivate a healthy attitude of self-esteem, self-confidence, rational peace, and positiveness. The essence of self-esteem, self-confidence, rational peace, and positiveness is prosocial [8]. In summary, this study is conducive to enrich crosscultural empirical research and explore the cultivating direction of Chinese university students' prosocial behavior. It has both theoretical and practical values.

1.1. Different Measures of Social Class. In different research fields, the research on social class uses different measurement scales. The measurement of social class in the fields of sociology and economics mainly uses objective social class indicators [9]. The objective social class, which also refers to the socioeconomics status (SES), consists of three specific indicators, included income, education, and occupational prestige. The measurement of social class in the field of psychology mainly uses subjective social class indicators $[10,11]$. Adler et al. developed the Macarthur Scale to measure subjective socioeconomic status [10]. The scale consists of a ladder with 10 levels, each level representing a different level of professional status, education level, and income level. Individuals determine their corresponding positions by comparing with other individuals in the organization. The higher the level selected by the subjects, the higher the level of their socioeconomic status. At present, more studies use the popular measurement procedure of social class, that is, a combination of subjective and objective methods to assess the social class of the subjects [12]. The MacArthur Scale (adult version) requires individuals to position themselves according to their position in the organization, according to the three indicators of education, income, and occupation, while the vast majority of young people are still studying in school, economically not yet independent, and with no full-time occupation. In order to meet the needs of measurement for adolescents, Goodman et al. revised the MacArthur Scale to form the MacArthur Scale (adolescent version) [13]. Therefore, we use the MacArthur Scale (adolescent version) to measure Chinese university students.

1.2. Different Measures of Prosocial Behavior. Prosocial behaviors have rich connotations, diverse types, and multiple measurement scales. Some researchers choose indicators such as donation behavior, voluntary service behavior, and daily helping behavior to measure prosocial behavior [2-4]. In the United States and Europe, there are relatively mature platforms to record data on these behavior indicators, and it is relatively easy to obtain relevant data. In China, this work has just started, and the abovementioned behavior indicator information is not directly available. Some researchers also use indicators such as social value orientation and social mindfulness to refer to prosocial behavior $[5,14,15]$. Data are obtained in the form of questionnaire surveys. These indicators are biased towards the measurement of prosocial tendencies and are not actual prosocial behaviors. Other researchers use economic games and decision-making in social dilemmas to measure prosocial behavior. The most representative ones are the dictator game and the trust game [2-4]. One-time dictator games can be used to test the generosity of individuals. The trust game is a game of multiple dictators played by the two parties in turn.

1.2.1. Dictator Game. Generosity is a typical manifestation of altruism and an important type of prosocial behavior. Unlike cooperation and win-win, generous people have to give their resources to others for free, without any monetary return. The generous donors of charitable donations consume their financial resources. The generous volunteers consume their limited time resources. During the epidemic prevention and control period, the generosity of members of the society is urgently needed.

Dictator game is originally used to test the economic assumptions of game theory [16]. The basic game process is as follows. Player 1 has a sum of money to share with Player 2. Player 1 has absolute control over the money and can propose any distribution plan. Player 2 can only accept and has no chance to refuse. The amount allocated by player 1 to player 2 is regarded as a measure of generosity. The results of this type of research show that the traditional economic theories about "people are selfish" are not supported by the game framework $[17,18]$. The literature in the field of economics shows that the standard distribution of dictator games is $50 / 50$ distribution, that is, half-to-half fair distribution. $86 \%$ of university students believe that $50 / 50$ distribution is an acceptable social behavior. In the dictator game, under special circumstances, no more than $25 \%$ of university students choose the 50/50 distribution. Whitt and Wilson found that more than $20 \%$ of dictators chose equal distribution [19]. The behavior of dictators in the game may be affected by social norms or group norms. The social environment of university campuses has obvious differences compared with nonuniversity environments. Through the dictator game, understanding the characteristics of generosity of university students is conducive to promoting the development of their prosocial behaviors. In the short term, it is conducive to the prevention and control of the epidemic in universities, to win the battle against the epidemic on campus, and to consolidate the fruits of victory in China's successful fight against the epidemic. In the long run, it is conducive to cultivating the prosocial mentality of the society as a whole, that is, self-esteem, self-confidence, rational peace, and positive social mentality.

1.2.2. Trust Game. Trust is one of the pillars of society. During the epidemic prevention and control period, people need to trust each other more. Without trust between people, there will be no intimacy, no economic transactions, and no successful epidemic prevention and control. If there is a lack of basic trust between people, the entire society will fall apart. Facts have proved that trust plays a vital role in the 
development and maintenance of close personal relationships [20], as well as anonymous transactional relationships [21]. Correspondingly, trust will promote social cooperation [22], create value for the organization [23], and enhance compliance with government policies [24]. During the epidemic prevention and control period, attach importance to individual responsibility, enhance community cooperation, and comply with epidemic prevention policies. Individuals need to trust others, trust the community, and trust the government. Although a well-functioning society requires trust, not everyone can always be trusted. Research has found that people differ in trust and trustworthiness [25]. Researchers have found that trust and trustworthiness are closely related to facial expressions [26], personality [27], and leadership styles [28].

The trust game, originally called the investment game, has been developed for more than 20 years. The basic game process is as follows. The two players, called player 1 and player 2 , are given equal amounts of money, denoted as $S$. In the first round of the game, player 1 first takes out a part of his own money and allocates it to player 2, denoted as $y$. Usually, this $y$ is multiplied by a given coefficient and then assigned to player 2 . The size of the coefficient varies from research to research, usually the coefficient is 3 ; that is, player 2 gets $3 y$. After the first round of the game, the amount of money of player 1 is $S-y$, and the amount of money of player 2 is $S+3 y$. In the second round of the game, player 2 returns a certain amount of money from $3 y$ to player 1, and the returned amount is recorded as $x, 0 \leqq x \leqq 3 y$. After the second round of the game, the amount of money for player 1 is $S-y+x$, and the amount of money for player 2 is $S+3 y-x$. In the first round of the game, the distribution amount of player 1 can be regarded as a measure of trust. In the second round of the game, the amount returned by player 2 can be regarded as a measure of trustworthiness [29].

\section{Study 1: The Influence of Social Class on University Students' Generosity in the Dictator Game}

\subsection{Method}

2.1.1. Participants and Experimental Design. Participants came from a university in Anhui, freshmen in the public compulsory course "Psychological Health Education for University Students." There are a total of 320, including 235 boys and 85 girls. Adopt 2(self-social class: high/low) $\times$ 2(target social class: high/low) between-subjects design experiment; the dependent variable is the assigned score of the participant in the dictator game.

2.1.2. Procedure. In the classroom of the "Mental Health Education for University Students" course, the teacher sends the online research link address to the whole class in charge of the online teaching platform, and the students can start the investigation by clicking the link address on their mobile phones.
Firstly, students complete the assessment of their social class through the two ladders of the MacArthur Scale (adolescent version). The first ladder with 10 levels depicts the possible levels of all members of Chinese society. (1) At the top of the ladder stand the best people. They are the richest, have the highest level of education, and are doing the best work. (2) At the end of the ladder are the people who are in the worst conditions, who have the least money, have a low level of education, or have never received education, are unemployed, or are doing the least respected work. Now, please think about it. On which level of the ladder can your family be placed? Please fill in the ladder level in the air. The second ladder with 10 levels of ladders depicts the situation of all students in the school where the university students are located. (1) At the top of the ladder stands the most respected, best-achieving, and highest-status student in your school; (2) at the end of the ladder stand the most scorned classmates with the worst grades. No one wants to be with them. Now, please think about it. On which level of the ladder would you place yourself? Please fill in the ladder level in the air.

Secondly, manipulate target social class by assigning different instructions. In the group of the high target social class, the instruction that all students read is as follows: You will complete a computer-based decision-making task with a specific student. This partner is at the top of the ladder and is the most respected in the same grade and has the best grades and highest status. In the group of the low target social class, the instruction that all students read is as follows: You will complete a computer-based decision-making task with a specific student. This partner is at the bottom of the ladder, is the most underestimated student in the same grade, has the worst grade, and has the lowest status.

Thirdly, in order to test the effectiveness of manipulation, the subjects were required to use the MacArthur Scale (adolescent version) to assess the social class of their peers, just as the subjects evaluated their own class.

Finally, students complete the distribution decision of the dictator game. The instruction is as follows: now there are 100 points of course points that need to be allocated between you and your peers. You are in the role of proposer and your peer is in the role of receiver. The score assigned to your peer is between 0 and 100 . Companions can only accept the results of the distribution, but cannot refuse. The result of the allocation depends entirely on your allocation. The assignment is completely anonymous, and you neither know nor meet with another companion. After the quiz is completed, make a prudent explanation.

\subsection{Results}

2.2.1. Selection of Subjects from High and Low Social Classes. Regression analysis is performed with family social class as the independent variable and self-social class as the dependent variable. The results show that the relationship between the subjective ratings of family social class and selfsocial class is significant $(\beta=0.32, t=4.402, p<0.001)$. The data prove that the subjective evaluation of the MacArthur 
Scale (adolescent version) can effectively distinguish the social class of the subjects.

The MacArthur Scale was scored using the Likert 10point scale. In order to distinguish between high and low social classes, the ordinal scale needs to be converted into a category scale. Sort the subjective social classes of all students in the class, and take $27 \%$ of the front and back as representatives of the high and low classes [30]. The sample size is 320 people, 86 high self-social class subjects ( 52 boys, 34 girls, $M_{\text {high }}=7.83, S D=1.02$ ) and 86 low self-social class subjects ( 51 boys, 35 girls, $M_{\text {low }}=2.59, S D=0.84$ ).

2.2.2. Testing the Effectiveness of Target Social Class Manipulation. In order to test the effectiveness of the target social class manipulation, the target social class is used as the grouping variable, and the peer's rating is used as the dependent variable, and the independent sample $t$ test is performed. The results show that there is a significant difference in the social class ratings of the peers between the two groups, $t(170)=29.03, p<0.001$. Compared with the peers in the low target social class group, subjects in the high target social class group rated their peers' social class higher $\left(M_{\text {high }}=8.26, S D=1.26 ; M_{\text {low }}=2.97, S D=1.11\right)$. The data proves that the manipulation of the target social class is effective (see Figure 1).

\subsubsection{Class Difference Test of Prosocial Behavior.} Investigate the main effects of the two factors of self-social class and target social class, as well as the interactive effects between the two. Self-social class (high/low) and target social class (high/low) are independent variables, and the distribution score in the dictator game is the dependent variable, and two-way between-subjects ANOVA is performed. The results show that the main effect of self-social class is not significant, $F(1,168)=2.001, p=0.159$. The main effect of the target social class is significant, $F(1,168)=24.909, p=<0.001$. Participants in high target social class group assigned more scores to their peers $\left(M_{\text {High target social class }}=46.58 \mathrm{VS} M_{\text {Low }}\right.$ target social class $=42.23)$. The interaction effect between selfsocial class and target social class is significant, $F(1,168)=$ 84.783, $p<0.001$ (see Table 1 and Table 2, Figure 2).

In order to test the specific impact of the interaction effect of the two factors, the simple effect test is continued. According to the research needs, the effect of the target social class is examined under the condition of fixing self-social class. Among the subjects in the low self-social class, the main effect of the target social class is significant, $F(1,169)=$ $100.801, p<0.001$, and participants in the high target social class group were assigned more points. Among the subjects in the high self-social class, the main effect of the target social class is significant, $F(1,169)=8.891, p=0.003$, and participants in the low target social class group were assigned more points (see Table 3 ).

2.3. Discussion. Based on the dictator game, study 1 explores the influence of social class on the prosocial behavior of university students under the dictator game. The study found that the self-social class lacks an influential effect on prosocial behavior, which is consistent with the findings of Van Doesum et al. [5], but it is inconsistent with the findings of Piff et al. [2-4].The target social class has an influential effect on prosocial behavior. The findings of Van Doesum et al. also prove the importance of target social class [5]. Self-social class and the target social class have an interactive effect. Participants in self-social class showed greater prosociality when facing low target social class, which is consistent with the findings of Van Doesum et al. [5]. In the low self-social class, participants showed greater prosociality when facing high target social class, which is inconsistent with the findings of Van Doesum et al. [5]. It can be seen that the influence of target social class on prosocial behavior is complex and cannot be discussed in one go.

How to explain the above research results? Firstly, the influence of self-social class on prosocial behavior has not been confirmed in this study. In other words, self-social class alone cannot influence prosocial behavior. Prosocial behaviors widely exist in the two classes of campus "Xue Ba" and "Xue Zha." Can the conclusions drawn from Chinese university campuses be extended to the entire Chinese society? Taking China's entire society united to fight the epidemic as an example, Tencent's antiepidemic fund was 88 million yuan to help epidemic research and medical care; Didi Chuxing established a medical care security fleet and community security fleet to provide free emergency travel services. Numerous volunteers stepped forward, and medical staff, community volunteers, and hospital volunteers rushed to the front line of the fight against the epidemic, "working hard" for China's epidemic prevention and control. Prosocial behaviors in the prevention and control of the epidemic are widely present in different social class. Secondly, the influence of target social class on prosocial behavior is confirmed in this research. However, the influence of target social class on prosocial behavior is regulated by self-social class. The higher the individual's social class, the more prosocial the individual when faced with low target social class, which confirms the perspective of fairness and echoes the idea of "being good at the world" [31]. The lower the individual's social class, the more prosocial the individual when faced with high target social class, which confirms the perspective of status and denies that "poor is good for oneself"; objectively it is easy to form the "Matthew effect."

\section{Study 2: The Influence of Social Class on University Students' Trust Behavior in the Trust Game}

\subsection{Method}

3.1.1. Participants and Experimental Design. Participants came from a university in Anhui, freshmen in the public compulsory course "Psychological Health Education for University Students." There are a total of 176, including 92 boys and 84 girls. Adopt 2 (self-social class: high/low) $\times$ 


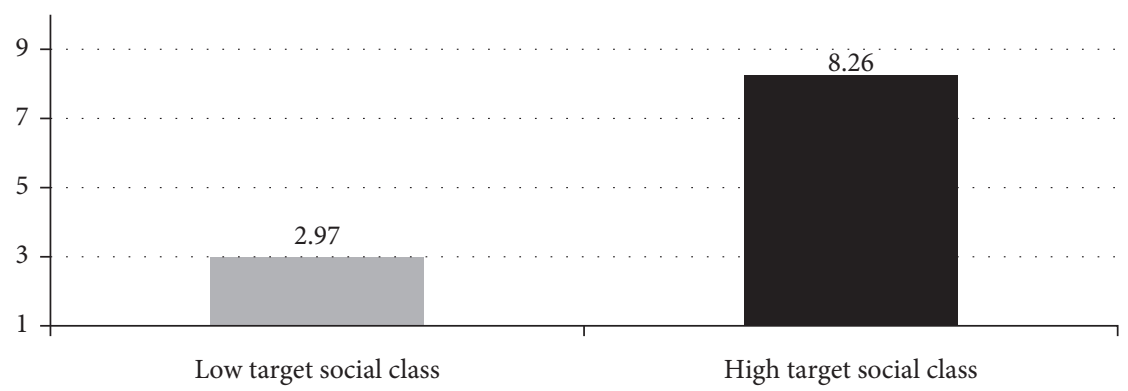

FIGURE 1: Rating of peers from different group of target social class.

TABLE 1: Means and standard deviations of the number of points in a dictator game per condition in the study.

\begin{tabular}{lccccc}
\hline \multirow{2}{*}{ Number of points sent } & Low target social class & \multicolumn{3}{c}{ High target social class } \\
& $N$ & $M$ & SD & $N$ & SD \\
\hline Low self-social class & 43 & 37.60 & 3.99 & 43 & 49.98 \\
High self-social class & 43 & 46.86 & 5.89 & 43 & 43.19 \\
\hline
\end{tabular}

TABLE 2: The ANOVA results of two-factor between-subjects experiment design.

\begin{tabular}{|c|c|c|c|c|c|}
\hline Source & Type III sum of squares & Df & Mean square & $F$ & Sig. \\
\hline Self-social class & 65.326 & 1 & 65.326 & 2.001 & 0.159 \\
\hline Target social class & 813.233 & 1 & 813.233 & 24.909 & 0.000 \\
\hline Self-social class $*$ target social class & $2,768.023$ & 1 & $2,768.023$ & 84.783 & 0.000 \\
\hline Error & $5,484.930$ & 168 & 32.648 & - & - \\
\hline Total & $348,312.000$ & 172 & - & - & - \\
\hline Corrected total & $9,131.512$ & 171 & - & - & - \\
\hline
\end{tabular}

a. $R$ squared $=.399$ (adjusted $R$ squared $=.389$ ); $b$. dependent variable: the number of points in a dictator game.

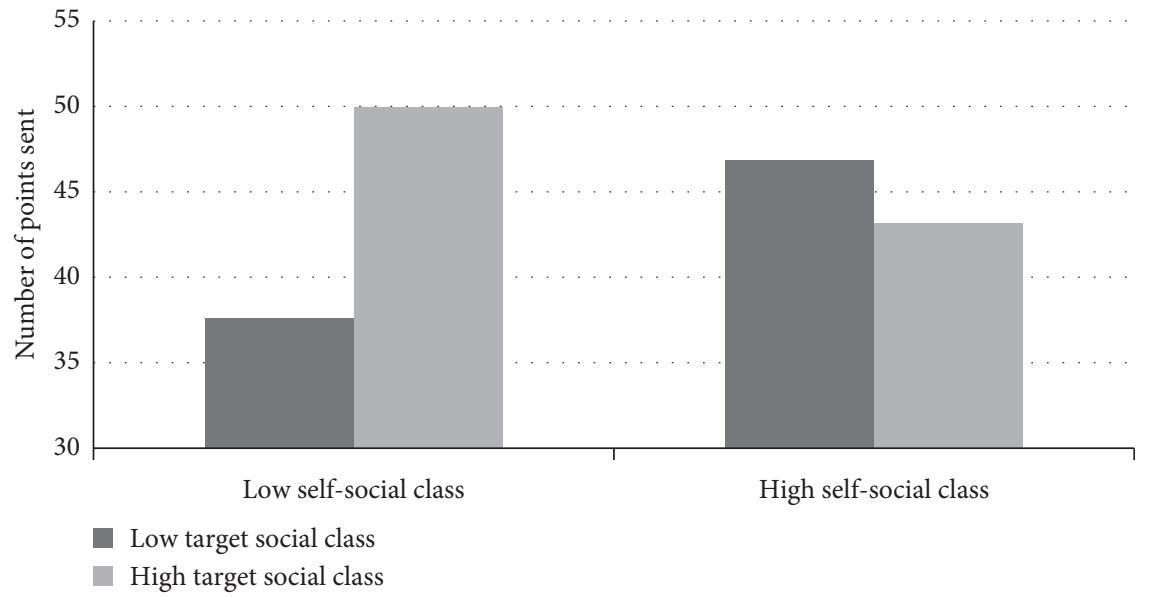

Figure 2: The effect of social class on the number of points in the dictator game from China college students.

TABLE 3: The ANOVA results of the test of simple effect.

\begin{tabular}{lcccc}
\hline Source of variation & Sum of squares & Df & Mean square & F \\
\hline Within + residual & $5,484.930$ & 168 & 32.648 & \\
Target social class within low self-social class & $3,290.977$ & 1 & $3,290.977$ & 100.801 \\
Target social class within high self-social class & 290.279 & 1 & 290.279 & 0.000 \\
\hline
\end{tabular}

a. Dependent variable: the number of points in a dictator game. 
2(target social class: high/low) between-subjects design experiment, and the dependent variable is the assigned score of the participant in the trust game.

3.1.2. Procedure. In the classroom of the "Mental Health Education for University Students" course, the teacher sends the online research link address to the whole class in charge of the online teaching platform, and the students can start the investigation by clicking the link address on their mobile phones.

Firstly, referring to the procedure of Study 1, students complete the MacArthur Subjective Socioeconomic Status Scale (adolescent version), which is used to assess self-social class. Secondly, referring to the procedure of Study 1, by assigning different instructions, manipulate target social class. Thirdly, students complete the distribution decision of the trust game. The instruction is as follows: you have 30 points for the course, and your partner also has 30 points for the course, which is recorded as S. You can allocate a part of the 30 points to your peers and record it as $y$. Your partner's course points will increase by $3 y$, and the increase will be 3 times the assigned points. After your assignment, your course is divided into $S-y$, and the course of your partner is divided into $S+3 y$. Next, it will be the partner's turn to assign. The partner chooses to return a part of the score from $3 y$, denoted as $x, 0 \leqq x \leqq 3 y$. After the assignment of your partner, your course is divided into $S-y+x$, and your partner's course is divided into $S+3 y-x$. In the two rounds of allocation, you play the role of the principal, and your partner plays the role of the agent. You will compete with everyone who participates in the survey in order to get more points. After all the subjects completed their assignments, the teacher told the subjects that they did not pair with their peers to make decisions and elaborated on the research hypothesis. After careful explanation, thank the students for their participation.

In fact, the participant did not make a decision with a partner, but only completed the distribution part of the trust game. In this trust game, the betrayal of the peer is a possible risk that the subjects need to bear. The trust of the subjects means that they are willing to assign scores to their peers, so that their peers benefit, and their potential costs rise. Therefore, the number of points assigned by the subjects to their peers is an observational indicator of prosocial behavior.

\subsection{Results}

3.2.1. Main Effect of Self-Social Class. Taking self-social class as the independent variable and taking the scores in the trust game as the dependent variable, regression analysis is carried out. The results show that the relationship between the selfsocial class and the score of the trust game is not significant $(\beta=0.001, t=0.014, p=0.989)$. The research results show that the main effect of self-social class is not significant. In the trust game, there is no significant difference in the distribution of scores of the participants of each class (see Figure 3).
3.2.2. Main Effect of Target Social Class. Taking target social class as the grouping variable and taking the scores in the trust game as the dependent variable, the independent sample $t$ test is carried out.

The results show that there is a significant difference in the distribution scores of the two groups of subjects in the trust game, $t(174)=17.643, p<0.001$. Compared with the participants in the low target social class group, the high target social class group had a higher distribution score in the trust game $\left(M_{\text {high }}=15.147, S D=1.623 ; M_{\text {low }}=10.602\right.$, $S D=1.791)$. The research results show that the main effect of the target social class is significant (see Figure 4).

\subsubsection{The Interaction Effect between Self-Social Class and} Target Social Class. Refer to study 1, sort subjective social class of all students in the class, and take $27 \%$ of the front and back as representatives of the high and low class. The sample size is 176,47 high self-social class subjects (30 boys, 17 girls) and 47 low self-social class subjects ( 25 boys, 22 girls).

In order to examine the main effects of self-social class and target social class, as well as the interactive effects between the two, self-social class (high/low) and target social class (high/low) are used as independent variables. The score assigned in the trust game is the dependent variable, and a two-way between-subjects ANOVA is performed. The results show that the main effect of self-social class is not significant, $F(1,90)=0.41, p=0.524$. The main effect of target social class is significant, $F(1,90)=238.468, p<0.001$; the subjects in high target social class group assigned more scores to their peers $\left(M_{\text {High target social class }}=15.41 \mathrm{VS} M_{\text {Low }}\right.$ target social class $=11.19)$. The interaction effect between selfsocial class and target social class is not significant, $F(1,90)=$ 1.295, $p=0.258$ (see Table 4 and Table 5; Figure 5).

3.3. Discussion. Study 2 is based on the trust game paradigm and explores the influence of social class on prosocial behavior of university students. The study found that selfsocial class lacks an influential effect on prosocial behavior, which is consistent with the findings of Study 1 . Target social class has an influential effect on prosocial behavior, which is consistent with the findings of Study 1. Self-social class and target social class do not have interaction effect, which is inconsistent with the findings of Study 1. Regardless of the level of the subjects' social class, they all showed greater prosociality when facing high target social class.

How to explain the above research results? Firstly, the influence of self-social class on prosocial behavior is also unproven in Study 2. As mentioned earlier, trust is one of the important pillars of society. Without trust, the entire society will fall apart. This is true of the bottom society, and the same is true of the upper society. Regardless of class level, there is no essential difference in the level of trust shown by individuals. On university campuses, both university students from impoverished mountainous areas or from prosperous metropolises have the closest and intimate friends, and the place of origin does not hinder the formation of intimate relationships. In online shopping transaction payment, cashless online payment is a common phenomenon. 


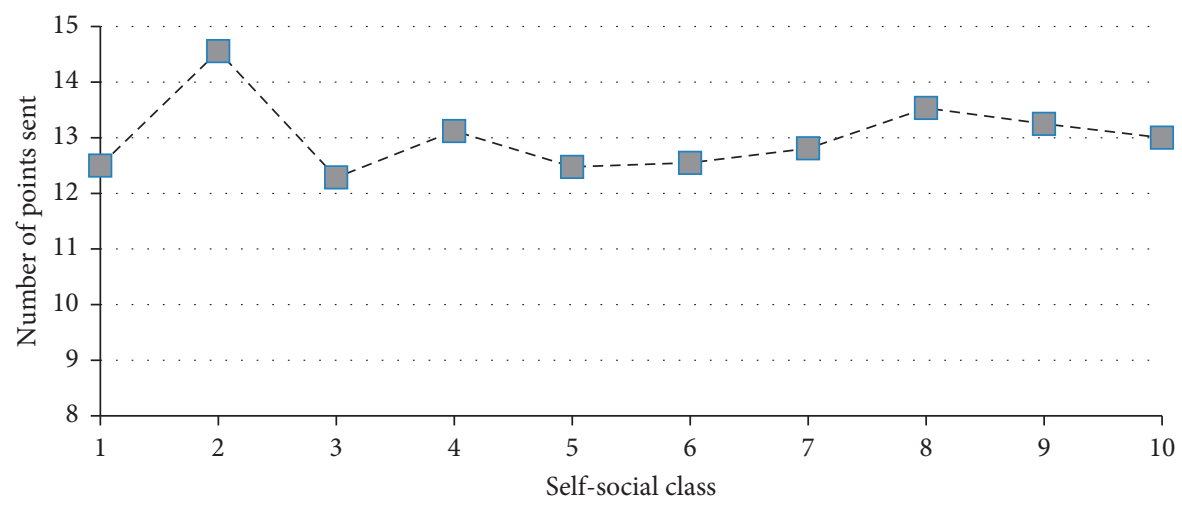

FIGURE 3: The effect of self-social class on the number of points in a trust game from China university students.

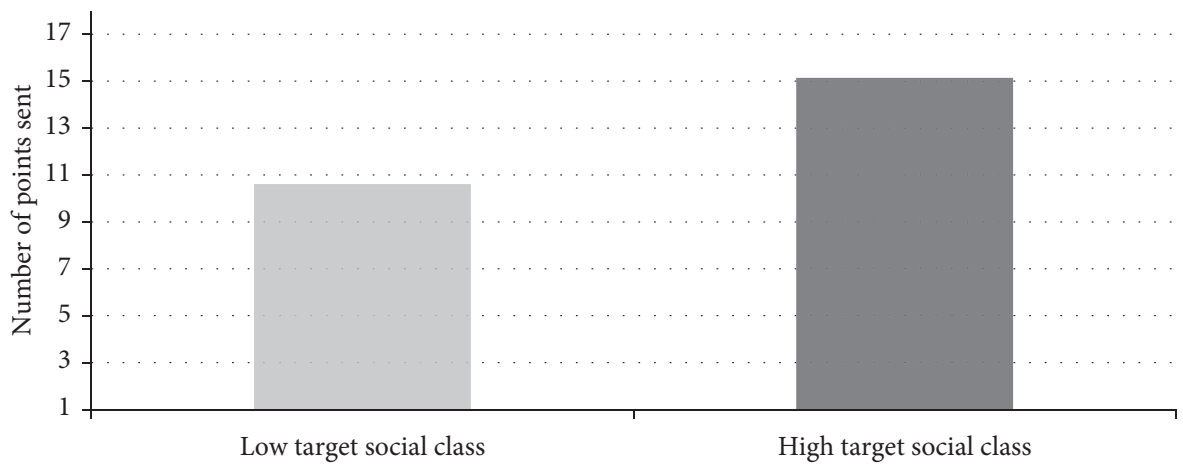

FIGURE 4: The effect of target social class on the number of points in a trust game from China university students.

TABLE 4: Means and standard deviations of the number of points in a trust game per condition in the study.

\begin{tabular}{lcccccc}
\hline \multirow{2}{*}{ Number of points sent } & \multicolumn{3}{c}{$\begin{array}{c}\text { Low target social } \\
\text { class }\end{array}$} & \multicolumn{3}{c}{$\begin{array}{c}\text { High target social } \\
\text { class }\end{array}$} \\
& $\mathrm{N}$ & $\mathrm{M}$ & $\mathrm{SD}$ & $\mathrm{N}$ & $\mathrm{M}$ & $\mathrm{SD}$ \\
\hline Low self-social class & 23 & 11.26 & 1.74 & 24 & 15.17 & 1.13 \\
High self-social class & 24 & 11.13 & 1.15 & 23 & 15.65 & 1.19 \\
\hline
\end{tabular}

University students show the same level of trust in unfamiliar transactions. The difference lies in the shopping platform and the choice of payment platform. In complying with the epidemic prevention and control policies, university students did not show obvious class differences, and university students generally showed a high degree of trust in the government's epidemic prevention policies. During the national epidemic clearance stage, university students confidently walked out of campus, flowed normally, and lived a normal life. During the sporadic epidemic, university students do not go to high-risk and medium-risk areas and live freely in low-risk areas. In general, university students have shown a high degree of trust in the government's antiepidemic policy.

Secondly, the influence of target social class on prosocial behavior was confirmed again in Study 2. Both generosity and trust behavior are significantly affected by the target social class. The difference is that the influence of target social class on generosity is regulated by self-social class, while the influence of target social class on trust behavior is not regulated by self-social class. The higher the class is, the easier it is to win trust. Trust is both important and grounded. The better the grades, the higher the status, and the better the character of university students, the easier it is to win the trust of their classmates. This is the basis for the trust of peers of university students. Learning from high school as a teacher and being a model is the basis for teachers to win the trust of students. Fair law enforcement is the basis for the police to win the trust of the people. The more effective the epidemic prevention and control are, the more it can win the trust of the people. This is the basis for the Chinese government to fight the epidemic and win the trust of the people.

\section{General Discussion}

In recent years, the influence of social class on prosocial behavior has been full of disputes and contradictions. In particular, the measurement methods of social class are different, the indicators of prosocial behavior measurement are very rich, and the sources of research samples are extremely different, which makes this kind of controversy more complicated. Adopting a research paradigm, locking in a research direction, and maintaining the repeatability and verifiability of research are important directions for resolving disputes. Based on the game research paradigm, this research uses the dictator game and the trust game as research tools to explore the influence of social class on 
TABLE 5: The ANOVA results of two-factor between-subjects experiment design.

\begin{tabular}{lcccc}
\hline Source & Type III sum of squares & Df & Mean square & F \\
\hline Self-social class & 0.718 & 1 & 0.718 & 0.410 \\
Target social class & 417.611 & 1 & 417.611 & 0.524 \\
Self-social class $*$ target social class & 2.267 & 1 & 2.267 & 0.000 \\
Error & 157.611 & 90 & 1.751 & 1.295 \\
-Total & 17200.000 & 94 & - & - \\
Corrected total & 577.660 & 93 & - & - \\
\hline
\end{tabular}

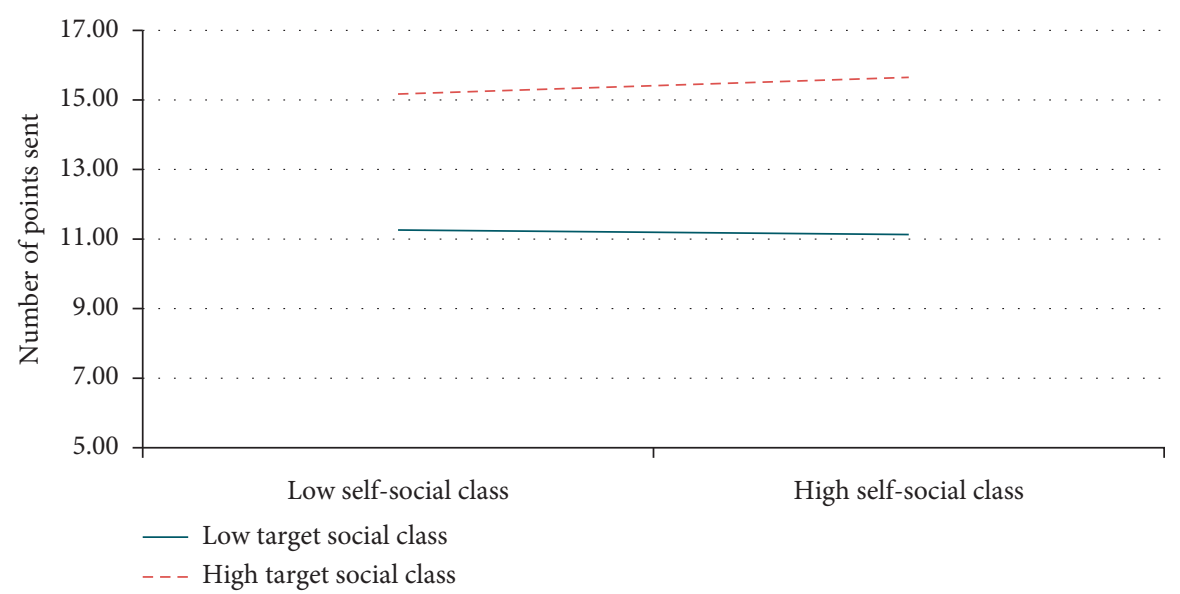

Figure 5: The effect of social class on the number of points in a trust game from China university students.

prosocial behavior of Chinese university students. The research results show that, in the two game situations, selfsocial class has no effect on prosocial behavior of university students, and target social class has a significant impact on prosocial behavior of university students. Under the dictator game, there is an interactive effect between self-social class and target social class, while under the trust game, there is no interaction effect between self-social class and target social class.

So, what are the characteristics of the distribution behavior in the dictator game? A study on a sample of 514 Japanese nonstudents found that cognitive ability and age can affect the distribution behavior of the dictator game. Among them, there is a negative correlation between cognitive ability and the distribution in the dictator game. The higher the cognitive ability, the lower the distribution amount; the age and the distribution in the dictator game have a positive correlation. The older the age, the greater the distribution amount [32]. In the study of the dictator game with adults as a sample, a fair hypothesis was found. But fairness may be affected by personality traits and situational factors. A study with 164 elementary school children as a sample found that the situation (dictator game/ultimatum game) and the personality characteristics of honesty and humility have predictive effects on the distribution in the game. Compared with the dictator game, children in the ultimatum game provide more candies; honest and humble children provide more candies [33]. An experimental evidence from Pakistan shows that there are gender differences in the generosity of the dictator game; the donations of subjects with higher religious beliefs are much more than those of subjects with lower religious beliefs [34]. Different experimental method of the dictator game can examine a wealth of potential strategic motivations. Experiments have shown that the fully rational hypothesis is unsatisfactory in explaining the dictator game. Regarding the preference effect of social class, gender, and country variables in the game of dictators, so far, previous studies have had many conclusions, but the actual situation may be relatively vague and complicated [35]. A considerable number of researchers attribute the differences in the distribution of the dictator game to demographic variables. However, research on high school students found that the higher the scores of dictator are on the Social Generosity Scale, the more likely they are to comply with the 50/50 rule. The higher the score of the dictator on the independence scale, the less allocated to the recipient [36]. Behavioral science research proves that the selfish preferences of human individuals are limited. There is convincing evidence that people's preferences and decisionmaking are determined by interpersonal relationships and interaction situations. The researchers found in a single game that $4 / 5$ of the dictators worked hard to reduce social distance. Using this as a decision-making framework, the dictator judges whether the recipient "should get more" or "should get less" [37]. Combining the findings of Study 1, we can see that, under the framework of the dictator game, the mechanism of prosocial behavior is complicated. Demographic variables such as age, gender, religious beliefs, and social class must also be considered; also consider the variables of personality traits such as social generosity and independence, but also consider the decision-making context variables. 
What are the characteristics of the distribution behavior in the trust game? Trust and trustworthiness are important components of social cohesion and productivity. In experimental economics, the trust game is used as a measure of trust and trustworthiness behavior. At present, there are many research literatures that use trust game to explore the relationship between trust and demographic variables such as age and gender. A trust game experiment on university students in Austria shows that trust and trustworthiness have an age effect. The older the age, the higher the trust and the higher the trustworthiness [38]. In the trust game, men have a higher degree of trust, and there is no significant gender difference in credibility [39]. Existing studies have shown that single subject variables such as gender and age can predict trust behavior. Study 2 found that target social class can effectively predict the trust behavior of the subjects. This shows that building trust is both complicated and simple. It must be noted that certain single information may win trust. This is an important feature of this prosocial behavior of trust.

The contribution of this research to the field of social class and prosocial behavior is as follows: first, we pay attention to the interactive influence of self-social class and target social class, which makes up for the limitation of only focusing on self-social class; second, we provide a sample of Chinese university students; the data has enriched the empirical evidence for cross-cultural research. Third, a comparative study of the distribution behavior under the dictator game and the trust game is carried out.

The deficiencies and future directions of this research: first, the measurement samples are not from the same group. There is no way to select measurement samples to fully replicate previous studies. Sample differences exist objectively. Although statistical techniques are adopted to control, this difference is of course ignored, but its potential impact on the research results still needs to be specifically pointed out. Second, the independent variable of social class does not use a combination of objective and subjective measurement methods. This is a big difference between this study and previous studies. The promotion and application of the research results should be extremely cautious. It is rational to limit the application to university campuses. Third, the measurement of the dependent variable is relatively single. Although the dictator game is the classic paradigm of the game research paradigm, it has been proven to be an effective means of measuring human cooperative behavior, but the scope of prosocial behavior is wide, and the available measurement methods are very rich. Future research should choose more measurements for more verification.

\section{Conclusion}

"If you are poor, you will be good for yourself, and if you are good, you will be good at the world." Is it the way of life for contemporary Chinese university students? This study confirms that looking at "poor" and "good" in isolation cannot effectively explain prosocial behavior of university students. Through the comparison of social class, the "poor" and "good" class status of university students will lead to diametrically opposite prosocial behavior. Specifically, our research found that

(1) In both the dictator game and the trust game, selfsocial class cannot effectively predict prosocial behavior of university students.

(2) In the dictator game, the influence of target social class on the prosocial behavior of university students is regulated by self-social class. In the trust game, the influence of target social class on the prosocial behavior of university students is not regulated by the self-social class.

\section{Data Availability}

The data used to support the findings of this study are included within the article.

\section{Conflicts of Interest}

The authors declare that there are no conflicts of interest regarding the publication of this paper.

\section{Acknowledgments}

This study was funded by the Humanities and Social Sciences Research Project of Bengbu University (2020SK03zd), the Quality Engineering Project of Universities in Anhui Province (2020szsfkc0589), the Teaching and Research Fund Project of the Education Department of Anhui Province (2020jyxm0017 and 2018jyxm1305), "First-class Course" of Anhui University of Finance and Economics (acylkc202008), and the Teaching and Research Fund Project of the Anhui University of Finance and Economics (acjyyb2020011 and acjyyb2020014).

\section{References}

[1] Y. Kou, Y. Ma, and C. Tan, "Undergraduates' prosocial tendencies, prosocial reasoning and their related models," Psychological Science, vol. 27, no. 2, pp. 329-332, 2004.

[2] P. K. Piff, M. W. Kraus, S. Côté, B. H. Cheng, and D. Keltner, "Having less, giving more: the influence of social class on prosocial behavior," Journal of Personality and Social Psychology, vol. 99, no. 5, pp. 771-784, 2010.

[3] M. Korndörfer, B. Egloff, and S. C. Schmukle, "A large scale test of the effect of social class on prosocial behavior," PloS One, vol. 10, no. 7, Article ID e0133193, 2015.

[4] A. Stamos, F. Lange, S.-c. Huang, and S. Dewitte, "Having less, giving more? Two preregistered replications of the relationship between social class and prosocial behavior," Journal of Research in Personality, vol. 84, Article ID 103902, 2020.

[5] N. J. Van Doesum, J. M. Tybur, and P. A. M. Van Lange, "Class impressions: higher social class elicits lower prosociality," Journal of Experimental Social Psychology, vol. 68, pp. 11-20, 2017.

[6] P. N. Radmore, "Children's altruistic behavior in the dictator game," Evolution and Human Behavior, vol. 28, no. 3, pp. 168-175, 2007.

[7] Y. Chen, L. Zhu, and Z. Chen, "Family income affects children's altruistic behavior in the dictator game," Plos One, vol. 8, no. 11, Article ID e80419, 2013. 
[8] Y. Kou, "Cultivation of prosocial mentality is an important part of social psychological service," Psychological Technology and Application, vol. 6, no. 10, p. 595, 2018.

[9] M. A. Diemer, R. S. Mistry, and M. E. Wadsworth, "Best practices in conceptualizing and measuring social class in psychological research," Analyses of Social Issues and Public Policy, vol. 13, no. 1, pp. 77-113, 2013.

[10] N. E. Adler, E. S. Epel, G. Castellazzo, and J. R. Ickovics, "Relationship of subjective and objective social status with psychological and physiological functioning: preliminary data in healthy, White women," Health Psychology, vol. 19, no. 6, pp. 586-592, 2000.

[11] M. W. Kraus, J. J. X. Tan, and M. B. Tannenbaum, "The social ladder: a rank-based perspective on social class," Psychological Inquiry, vol. 24, no. 2, pp. 81-96, 2013.

[12] M. W. Kraus and N. M. Stephens, "A road map for an emerging psychology of social class," Social \& Personality Psychology Compass, vol. 6, no. 9, pp. 642-656, 2012.

[13] E. Goodman, N. E. Adler, I. Kawachi, A. L. Frazier, B. Huang, and G. A. Colditz, "Adolescents' perceptions of social status: development and evaluation of a new indicator," Pediatrics, vol. 108 , no. 2 , pp. 1-8, 2001.

[14] R. O. Murphy and K. A. Ackermann, "Measuring social value orientation," Judgment \& Decision Making, vol. 6, no. 8, pp. 771-781, 2011.

[15] N. J. Van Doesum, D. A. W. Van Lange, and P. A. M. Van Lange, "Social mindfulness: skill and will to navigate the social world," Journal of Personality and Social Psychology, vol. 105, no. 1, pp. 86-103, 2013.

[16] R. Forsythe, J. L. Horowitz, N. E. Savin, and M. Sefton, "Fairness in simple bargaining experiments," Games and Economic Behavior, vol. 6, no. 3, pp. 347-369, 1994.

[17] E. Hoffman, "Social distance and other-regarding behavior in dictator games," American Economic Review, vol. 86, no. 3, pp. 653-660, 1996.

[18] G. Charness and U. Gneezy, "What's in a name? Anonymity and social distance in dictator and ultimatum games," Journal of Economic Behavior and Organization, vol. 68, no. 2, pp. 29-35, 2008.

[19] S. Whitt and R. K. Wilson, "The dictator game, fairness and ethnicity in Postwar Bosnia," American Journal of Political Science, vol. 51, no. 3, pp. 655-668, 2007.

[20] J. K. Mogilski, J. Vrabel, V. E. Mitchell, and L. L. M. Welling, "The primacy of trust within romantic relationships: evidence from conjoint analysis of HEXACO-derived personality profiles," Evolution and Human Behavior, vol. 40, no. 4, pp. 365-374, 2019.

[21] Y. Kim and R. A. Peterson, "A meta-analysis of online trust relationships in E-commerce," Journal of Interactive Marketing, vol. 38, pp. 44-54, 2017.

[22] D. Balliet and P. A. M. Van Lange, "Trust, punishment, and cooperation across 18 societies," Perspectives on Psychological Science, vol. 8, no. 4, pp. 363-379, 2013.

[23] C. Caldwell and K. K. Ndalamba, "Trust and being "worthy" the key to creating wealth," Journal of Management Development, vol. 36, no. 8, pp. 1076-1086, 2017.

[24] L. Batrancea, A. Nichita, J. Olsen et al., "Trust and power as determinants of tax compliance across 44 nations," Journal of Economic Psychology, vol. 74, p. 102191, 2019.

[25] I. Thielmann and B. E. Hilbig, "Trust: an integrative review from a person-situation perspective," Review of General Psychology, vol. 19, no. 3, pp. 249-277, 2015.

[26] D. Bzdok, R. Langner, S. Caspers, and F. Kurth, "ALE metaanalysis on facial judgments of trustworthiness and attractiveness," Brain Structure \& Function, vol. 215, no. 3-4, pp. 209-223, 2011.

[27] I. Thielmann, G. Spadaro, and D. Balliet, "Personality and prosocial behavior: a theoretical framework and meta-analysis," Psychological Bulletin, vol. 146, no. 1, pp. 30-90, 2020.

[28] K. T. Dirks and D. L. Ferrin, "The role of trust in organizational settings," Organization Science, vol. 12, no. 4, pp. 450-467, 2001.

[29] A. Ben-Ner and F. Halldorsson, "Trusting and trustworthiness: what are they, how to measure them, and what affects them," Journal of Economic Psychology, vol. 31, no. 1, pp. 64-79, 2010.

[30] H. L. Zhao, F. J. Xu, Y. Y. Guo, and S. L. Shu, "Class differences in prosocial behavior: dual perspectives of giving and receiving," Chinese Journal of Clinical Psychology, vol. 26, no. 5, pp. 841-846, 2018.

[31] X. Zheng, S. Peng, and L. Peng, "Feeling better and becoming MoreBenevolent: impact of social comparison on ProsocialBehavior," Acta Psychologica Sinica, vol. 47, no. 2, pp. 243-250, 2015.

[32] O. Kazuhito, K. Tetsuya, and M. Keiichiro, "Effects of cognitive ability and age on giving in dictator game experiments," Research in Economics, vol. 74, no. 4, pp. 323-335, 2020.

[33] A. Katharina, A. Ś. Karolina, T. Ulrich, E. H. Benjamin, and Z. Ingo, "Honesty-humility and dictator and ultimatum game-giving in children," Journal of Research in Personality, vol. 85, Article ID 103907, 2020.

[34] U. Hamza, "Revisiting generosity in the dictator game: experimental evidence from Pakistan," Journal of Behavioral and Experimental Economics, vol. 84, Article ID 101503, 2020.

[35] D. G. Philip and H. N. Heinrich, "Rational altruism? On preference estimation and dictator game experiments," Games and Economic Behavior, vol. 119, pp. 309-338, 2020.

[36] E. Catherine, J. G. Philip, and A. J. Cathleen, "Social norms of sharing in high school: teen giving in the dictator game," Journal of Economic Behavior \& Organization, vol. 80, no. 3, pp. 603-612, 2011.

[37] T. Linda, L. C. Todd, M. M. David, and F. S. Jason, "Endogenous context in a dictator game," Journal of Behavioral and Experimental Economics, vol. 65, pp. 117-120, 2016.

[38] G. Ben and Z. Anita, "Trust and age: an experiment with current and former students," Economics Letters, vol. 81, pp. 37-39, 2019.

[39] R. V. Olmo, M. A. L. M. van Assenbc, M. Vugtde, and J. M. Wichertsb, "Sex differences in trust and trustworthiness: a meta-analysis of the trust game and the gift-exchange game," Journal of Economic Psychology, vol. 81, Article ID 102329, 2020. 